\title{
Bleaching of Hardwood Kraft Pulp with Manganese Peroxidase Secreted from Phanerochaete sordida YK-624
}

\author{
RYUICHIRO KONDO, ${ }^{*}$ KOICHI HARAZONO, AND KOKKI SAKAI \\ Department of Forest Products, Faculty of Agriculture, Kyushu University, Fukuoka 812, Japan
}

Received 31 May 1994/Accepted 14 September 1994

\begin{abstract}
In vitro bleaching of an unbleached hardwood kraft pulp was performed with manganese peroxidase (MnP) from the fungus Phanerochaete sordida YK-624. When the kraft pulp was treated with partially purified MnP in the presence of $\mathrm{MnSO}_{4}$, Tween 80, and sodium malonate with continuous addition of $\mathrm{H}_{2} \mathrm{O}_{2}$ at $37^{\circ} \mathrm{C}$ for 24 $\mathrm{h}$, the pulp brightness increased by about 10 points and the kappa number decreased by about 6 points compared with untreated pulp. The pulp brightness was also increased by 43 points to $75.5 \%$ by multiple (six) treatments with MnP combined with alkaline extraction. Our results indicate that in vitro degradation of residual lignin in hardwood kraft pulp with MnP is possible.
\end{abstract}

Some white rot fungi are known to selectively degrade lignin in wood. The residual lignin in kraft pulp is highly modified by alkaline condensation reactions; nevertheless, some fungi can delignify unbleached hardwood kraft pulp $(1,4,16)$ and softwood kraft pulp $(5,20)$. Biobleaching with white rot fungi, including Trametes (Coriolus) versicolor $(1,16,20)$ and fungus strain IZU-154 $(4,5,14)$, has been studied by workers in some laboratories, who sought to eliminate or reduce the use of chlorine-based chemicals in bleaching.

The extracellular ligninolytic enzyme system of Phanerochaete chrysosporium has been studied extensively in recent years. We know that lignin peroxidase (LiP), manganese peroxidase $(\mathrm{MnP})$, and laccase are enzymes that are associated with the degradation of lignin. There have been several reports of using in vitro enzyme treatments to bleach hardwood kraft pulp. Arbeloa et al. showed that treatment of unbleached kraft pulp with LiPs facilitated subsequent chemical bleaching (2). Bourbonnais and Paice demonstrated that unbleached kraft pulp was delignified with isolated laccase from $T$. versicolor in the presence of 2,2-azinobis-(3-ethylbenzthiazoline-6-sulfonate) and that methanol was released (3). It has also been reported that delignification of hardwood kraft pulp by MnP was observed, but the extensive brightening observed with the fungus was not achieved with MnP (17).

Recently, we showed that MnP plays an important role in the bleaching of unbleached hardwood kraft pulp by white rot fungi (7). Furthermore, we developed a cultivation system in which a membrane filter was used to prevent direct contact between hyphae and kraft pulp while allowing extracellular enzymes to attack the kraft pulp. By using this system we found that the level of secreted MnP activity in the filterable components was substantial during in vitro bleaching with Phanerochaete sordida YK-624 (9). Therefore, in this study, we examined in vitro bleaching of kraft pulp with $\mathrm{MnP}$ isolated from strain YK-624.

\section{MATERIALS AND METHODS}

Fungi. Fungus strain YK-624 (= ATCC 90872), which was isolated from decayed wood obtained from a forest and was identified as $P$. sordida (9), exhibited remarkable bleaching

\footnotetext{
* Corresponding author. Mailing address: Department of Forest Products, Faculty of Agriculture, Kyushu University, Hakozaki, Fukuoka 812, Japan. Phone: (92) 641-1101, ext. 6362. Fax: (92) 632-1956.
}

ability with kraft pulp (7). This fungus was maintained on potato dextrose agar (Difco Laboratories) slants.

Preparation of MnP. Strain YK-624 was grown on potato dextrose agar in petri plates (diameter, $9 \mathrm{~cm}$ ) for 3 days at $30^{\circ} \mathrm{C}$. The contents of one-quarter of each plate, which were homogenized in a liquid culture medium with a Waring blender, were inoculated into a $500-\mathrm{ml}$ Erlenmeyer flask containing $200 \mathrm{ml}$ of culture medium. The liquid medium was nitrogen limited. This medium contained $10 \mathrm{~g}$ of glucose per liter, $0.22 \mathrm{~g}$ of ammonium tartrate per liter $(1.2 \mathrm{mM}), 1.64 \mathrm{~g}$ of sodium acetate per liter $(20 \mathrm{mM}), 1.0 \mathrm{~g}$ of Tween 80 per liter, and Kirk's trace elements and salts (22); the $\mathrm{pH}$ was adjusted to 4.5 . The flasks were shaken at $30^{\circ} \mathrm{C}$ and $150 \mathrm{rpm}$. After 0.25 g of veratryl alcohol was added to the medium in each flask on day 3 , the flasks were purged with oxygen every day. After 7 days of incubation, the supernatant was separated from the mycelium by filtration through glass fiber. Polyethylene glycol (average molecular weight, 3,000) was added to the filtrate to make a $5 \%$ solution. The $\mathrm{pH}$ was then adjusted to 7.2 with $5 \mathrm{~N}$ aqueous $\mathrm{NaOH}$. After the slime was filtered off, the filtrate was loaded onto a DEAE-Sepharose (Pharmacia) column equilibrated with $20 \mathrm{mM}$ phosphate buffer ( $\mathrm{pH}$ 7.2). The column was eluted successively with the following buffers: $20 \mathrm{mM}$ phos-

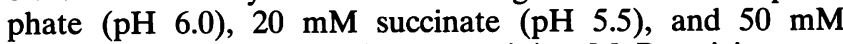
succinate ( $\mathrm{pH} 4.5)$. Fractions containing MnP activity were eluted with $50 \mathrm{mM}$ succinate ( $\mathrm{pH} \mathrm{4.5)}$. The partially purified MnP solution was used for pulp treatments (see below). Some of the MnP solution was subjected to anion-exchange chromatography (DEAE-Sepharose; Pharmacia) with a high-performance liquid chromatography (HPLC) system (Pharmacia LKB) consisting of a model 2249 gradient pump and a model UV-1 single-path monitor. The mobile phase was $20 \mathrm{mM}$ succinate ( $\mathrm{pH} 5.5$ ), and the flow rate was $2.0 \mathrm{ml} / \mathrm{min}$. Proteins were eluted with an $\mathrm{NaCl}$ gradient $(0$ to $5 \mathrm{M}) . A_{405}$ and $A_{280}$ were continuously monitored during elution. Sodium dodecyl sulfate (SDS)-polyacrylamide gel electrophoresis (PAGE) was performed, and the preparation was stained with Coomassie blue. Nondenaturing electrophoresis on $10 \%$ polyacrylamide gels was also performed. Proteins were visualized by Coomassie blue staining, and the MnP activity in nondenaturing gels was detected by incubating the gels with 2,6-dimethoxyphenol, $\mathrm{MnSO}_{4}$, and $\mathrm{H}_{2} \mathrm{O}_{2}$ in $50 \mathrm{mM}$ malonate buffer ( $\mathrm{pH} 4.5$ ).

Enzyme assays. A modification of the method of Perie and Gold (19) was used for the ligninolytic enzyme assays. MnP activity was assayed by monitoring the oxidation of 2,6-di- 
methoxyphenol at $470 \mathrm{~nm}$. The reaction mixtures contained 2,6-dimethoxyphenol $(1.0 \mathrm{mM}), \mathrm{H}_{2} \mathrm{O}_{2}(0.2 \mathrm{mM})$, and $\mathrm{MnSO}_{4}$ $(1.0 \mathrm{mM})$ in $50 \mathrm{mM}$ malonate buffer ( $\mathrm{pH} 4.5)$. MnP activity was expressed as the amount of spectral change (change in absorbance per minute). LiP activity was assayed by monitoring the oxidation of $1.7 \mathrm{mM}$ veratryl alcohol and $0.2 \mathrm{mM} \mathrm{H}_{2} \mathrm{O}_{2}$ in 20 $\mathrm{mM}$ succinate buffer ( $\mathrm{pH}$ 3.0). Phenol oxidase activity was assayed by monitoring the oxidation of 2,6-dimethoxyphenol at $470 \mathrm{~nm}$. The reaction mixtures contained $1.0 \mathrm{mM} 2,6$-dimethoxyphenol in $50 \mathrm{mM}$ malonate buffer ( $\mathrm{pH} 4.5)$. All enzyme assays were performed with 3-ml reaction mixtures at $37^{\circ} \mathrm{C}$.

Pulp treatments. An unbleached hardwood kraft pulp (brightness, 31.8\%; kappa number, 17.0) produced in an industrial pulp mill was used in this study. This pulp contained about $50 \mathrm{ppm}$ of manganese, as determined from ashed samples of pulp by inductively coupled plasma mass spectrometry. For pulp treatment with $\mathrm{Mn}^{3+}$, the kraft pulp was suspended at a consistency of $1 \%$ in $0.5 \mathrm{M}$ malonate buffer $(\mathrm{pH}$ 4.5) containing $20 \mathrm{mM}$ manganese(III) acetate. The headspace of a 200-ml Erlenmeyer flask containing the suspension was filled with nitrogen, and the flask was closed tightly with a stopper to maintain the stability of the $\mathrm{Mn}^{3+}$-malonate complex during pulp treatment. The suspension was stirred at room temperature for $24 \mathrm{~h}$. After treatment with $\mathrm{Mn}^{3+}$, the pulp was extracted with $0.25 \%$ aqueous $\mathrm{NaOH}$ at a pulp consistency of $10 \%$ for $2 \mathrm{~h}$ at room temperature. The treated pulp was then washed with distilled water and agitated in 50 $\mathrm{mM}$ malonate buffer ( $\mathrm{pH} \mathrm{4.5)}$ ) for $30 \mathrm{~min}$. The pulp treatment with $\mathrm{Mn}^{3+}$ described above was also performed in combination with alkaline extraction. As a control, the kraft pulp was treated in the same way except that manganese(III) acetate was not added.

For enzymatic treatments, the kraft pulp was suspended at a consistency of $1 \%(1 \mathrm{~g} / 100 \mathrm{ml})$ in $50 \mathrm{mM}$ malonate buffer $(\mathrm{pH}$ 4.5) containing $\mathrm{MnSO}_{4}, 0.05 \%$ Tween 80 , and an $\mathrm{MnP}$ solution. The suspension was stirred at $37^{\circ} \mathrm{C}$. The enzymatic reaction was started and maintained by continuously adding $\mathrm{H}_{2} \mathrm{O}_{2}$ at a flow rate of $3 \mathrm{ml} / \mathrm{h}$ with a peristaltic pump. The pulp was treated for $24 \mathrm{~h}$. Multiple treatments with MnP were also performed in combination with alkaline extraction. To enzyme treatment mixtures containing $1 \mathrm{~g}$ of kraft pulp, $100 \mathrm{U}$ of $\mathrm{MnP}$, $0.1 \mathrm{mM} \mathrm{MnSO}_{4}$, and $0.05 \%$ Tween 80 in $100 \mathrm{ml}$ of $50 \mathrm{mM}$ malonate buffer ( $\mathrm{pH} 4.5$ ), $10 \mathrm{mM} \mathrm{H}_{2} \mathrm{O}_{2}$ was added continuously at a flow rate of $3 \mathrm{ml} / \mathrm{h}$. Alkaline extraction after treatment with MnP was performed by using the process used for multiple treatments with $\mathrm{Mn}^{3+}$. As a control, the kraft pulp was treated in the same way except that $\mathrm{MnP}$ or $\mathrm{H}_{2} \mathrm{O}_{2}$ was not added.

Determination of residual $\mathrm{Mn}^{3+}$ content during pulp treatment. The residual $\mathrm{Mn}^{3+}$-malonate complex content during pulp treatment was determined as a function of time by measuring $A_{270}$ (28). Malonate buffer $(0.5 \mathrm{M}, \mathrm{pH} 4.5)$ containing $10 \mathrm{mM}$ manganese(III) acetate (Aldrich Chemical Co., Inc.) was stirred at room temperature for $24 \mathrm{~h}$ with or without $1 \% \mathrm{kraft}$ pulp under a nitrogen atmosphere or air. The $A_{270}$ of a 50-fold dilution of a sample of each stirred solution was determined; it seemed that few water-soluble lignin fragments absorbed in this region.

Pulp properties. After the pulp treatments and washing with distilled water, pulp sheets were prepared with a Buchner funnel to determine brightness. Pulp brightness was determined with a colorimeter (model CR-200; Minolta, Tokyo, Japan). The values determined with the colorimeter were multiplied by a coefficient to adjust them to ISO brightness values. The kappa number was determined by using TAPPI

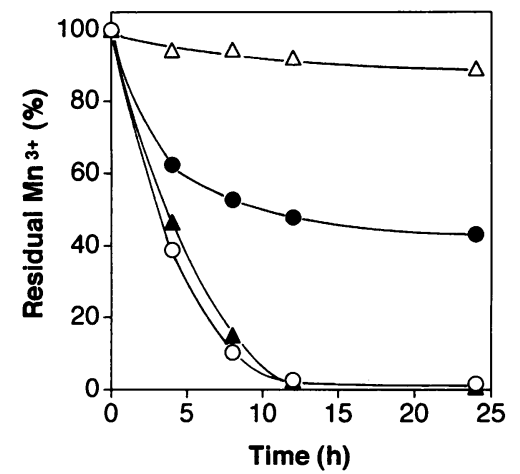

FIG. 1. Consumption of residual $\mathrm{Mn}^{3+}$-malonate complexes (initial concentration, $10 \mathrm{mM}$ ) as a function of reaction time. Symbols: $\bullet$, with pulp under a nitrogen atmosphere; $\boldsymbol{\Delta}$, without pulp under air; $\Delta$, without pulp under a nitrogen atmosphere; $\bigcirc$, with pulp under air.

useful method T236 (Technical Association of the Pulp and Paper Industry, Atlanta, Ga.).

\section{RESULTS}

Pulp treatments with $\mathrm{Mn}^{3+}$. Initially, a single treatment with $\mathrm{Mn}^{3+}$ was examined. The residual $\mathrm{Mn}^{3+}$-malonate complex content during stirring was determined as a function of time by measuring the $A_{270}$ (Fig. 1). The $\mathrm{Mn}^{3+}$-malonate complexes almost disappeared in the stirred solution incubated in the presence of air after $24 \mathrm{~h}$, while under a nitrogen atmosphere the $\mathrm{Mn}^{3+}$-malonate complex content was reduced by only $10 \%$ after $24 \mathrm{~h}$. The level of $\mathrm{Mn}^{3+}$-malonate complexes detected under a nitrogen atmosphere was reduced by $50 \%$ in the pulp suspension after $24 \mathrm{~h}$, which indicated that $\mathrm{Mn}^{3+}$ was consumed by the kraft pulp.

Higher concentrations of $\mathrm{Mn}^{3+}$ in the pulp treatment preparations resulted in increases in pulp brightness and decreases in the kappa number. However, the levels of brightness increase and kappa number decrease were only approximately 3 and 2 points, respectively (Fig. 2). Increasing the treatment time to more than $12 \mathrm{~h}$ did not improve delignification despite the presence of residual $\mathrm{Mn}^{3+}$-malonate complexes (Fig. 3). Multiple treatments with $\mathrm{Mn}^{3+}$-malonate complexes were also performed in combination with alkaline extraction. When pulp was treated with $\mathrm{Mn}^{3+}$ repeatedly, the pulp brightness increased (Fig. 4). When we repeated the $\mathrm{Mn}^{3+}$ treatmentalkaline extraction procedure five times, the brightness of the treated pulp was about 14 points higher than the brightness of

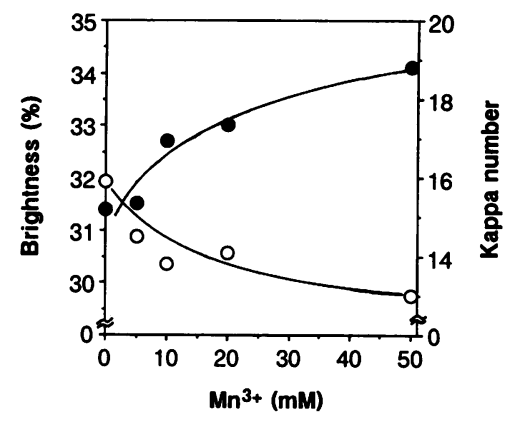

FIG. 2. Effect of $\mathrm{Mn}^{3+}$ concentration on brightness (๑) and kappa number $(O)$ of kraft pulp treated with $\mathrm{Mn}^{3+}$-malonate complexes for $24 \mathrm{~h}$ at room temperature. 


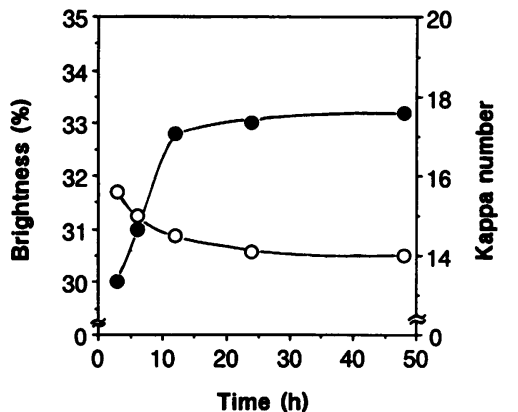

FIG. 3. Effect of treatment time on brightness ( $\bullet$ ) and kappa number $(O)$ of kraft pulp treated with $20 \mathrm{mM} \mathrm{Mn}^{3+}$ at room temperature.

a control treated without manganese(III) acetate; the kappa number was reduced by about 8 points (kappa number of the treated pulp, 5.5; kappa number of the control, 13.3).

Preparation of MnP. A supernatant from liquid cultures of fungus strain YK-624 was fractionated by anion-exchange chromatography. The MnP fraction used for enzymatic treatments produced two bands near a molecular mass of $45 \mathrm{kDa}$, as determined by SDS-PAGE (Fig. 5). Neither LiP nor phenol oxidase activity was detected in the MnP fraction. After part of the MnP solution was further purified by HPLC by using an anion-exchange column with a salt gradient, the same two bands were detected by SDS-PAGE. Both MnP solutions produced two bands when they were subjected to native PAGE (data not shown). The MnP solution isolated by the one-step procedure was used throughout this investigation because its bleaching effect was the same as the bleaching effect of the $\mathrm{MnP}$ isolated by the two-step procedure (data not shown).

Pulp treatments with MnP. Unbleached kraft pulp was treated under various conditions with an $\mathrm{MnP}$ solution fractionated by DEAE-Sepharose. First, the pulp was treated with $\mathrm{MnP}$ at concentrations ranging from 0 to $1,000 \mathrm{U}$ of $\mathrm{MnP}$ per $\mathrm{g}$ of pulp (Fig. 6). Initially, the pulp suspension contained $\mathrm{MnSO}_{4}$ at a concentration of $0.1 \mathrm{mM}$, and a $10 \mathrm{mM} \mathrm{H} \mathrm{H}_{2} \mathrm{O}_{2}$ solution was added at a rate of $3 \mathrm{ml} / \mathrm{h}$ for $24 \mathrm{~h}$. When the pulp was treated with 100 to $1,000 \mathrm{U}$ of $\mathrm{MnP}$, the brightness increased by about 10 points and the kappa number decreased by 6 points compared with the values for pulp treated without

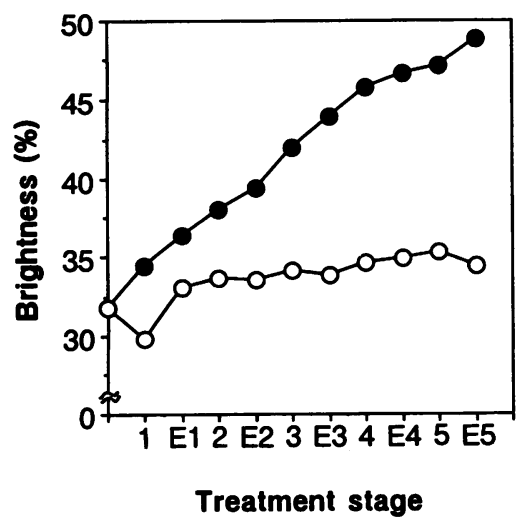

FIG. 4. Bleaching of kraft pulp with $20 \mathrm{mM} \mathrm{Mn}^{3+}$ combined with alkaline extraction. Symbols: , with $\mathrm{Mn}^{3+} ; \mathrm{O}$, without $\mathrm{Mn}^{3+}$. Treatment stages 1 through 5, $\mathrm{Mn}^{3+}$ treatment; treatment stages E1 through E5, alkaline extraction.

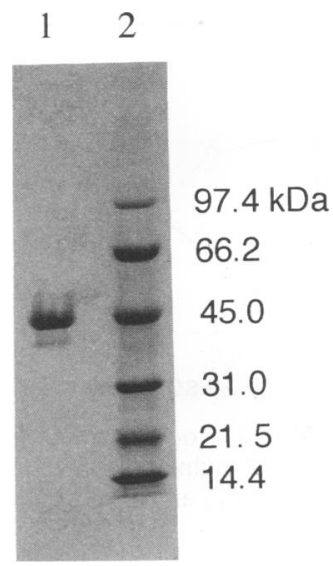

FIG. 5. SDS-PAGE of a solution containing $P$. sordida YK-624 MnP fractionated by DEAE-Sepharose (lane 1) and molecular mass standards (lane 2).

MnP. Delignification and brightening were also significantly influenced by the $\mathrm{MnSO}_{4}$ concentration (Fig. 7). When we added $100 \mathrm{U}$ of $\mathrm{MnP}$ and $10 \mathrm{mM}$ aqueous $\mathrm{H}_{2} \mathrm{O}_{2}$ at a rate of 3 $\mathrm{ml} / \mathrm{h}$, the pulp brightness increased remarkably in the presence of initial $\mathrm{MnSO}_{4}$ concentrations of 0.1 and $0.5 \mathrm{mM}$. When the pulp was treated with various concentrations of $\mathrm{H}_{2} \mathrm{O}_{2}$, addition of 5 and $10 \mathrm{mM}$ aqueous $\mathrm{H}_{2} \mathrm{O}_{2}$ most effectively increased the brightness of the pulp in the suspension containing $100 \mathrm{U}$ of $\mathrm{MnP}$ and $0.1 \mathrm{mM} \mathrm{MnSO}_{4}$ (Fig. 8a). In the presence of 1,000 U of $\mathrm{MnP}$, the brightness of the pulp increased by about 10 points and the kappa number decreased by about 6 points when we added $\mathrm{H}_{2} \mathrm{O}_{2}$ at concentrations ranging from 10 to $100 \mathrm{mM}$ at a rate of $3 \mathrm{ml} / \mathrm{h}$ (Fig. $8 \mathrm{~b}$ ). When the pulp was treated with 100 $\mathrm{U}$ of MnP without Tween 80, the brightness increased by only about 4 points, to $35.5 \%$. Therefore, the surfactant may be an important factor in the bleaching of pulp with MnP. When enzyme treatments were then repeated in combination with alkaline extraction, the pulp brightness increased to $70.3 \%$ after the fourth alkaline extraction and finally to $75.5 \%$ after the MnP treatment was repeated six times (Fig. 9).

\section{DISCUSSION}

Fungus strain YK-624 exhibited remarkable bleaching ability with kraft pulp (7) and brightened the pulp about 22 points after in vitro bleaching for 7 days in the membrane system which we used (9). It has also been shown that the increases in

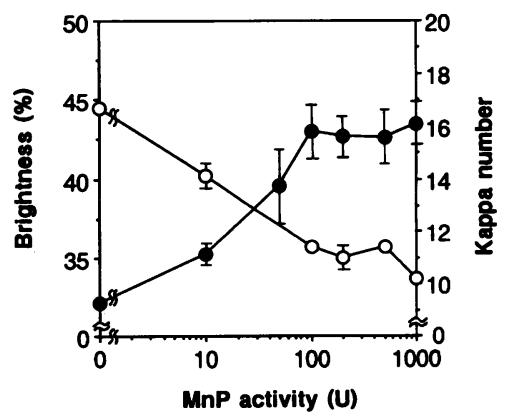

FIG. 6. Effect of $\mathrm{MnP}$ activity on brightness $(\Theta)$ and kappa number (O) of kraft pulp. Reactions were performed with $0.1 \mathrm{mM} \mathrm{MnSO}_{4}$, and $10 \mathrm{mM}$ aqueous $\mathrm{H}_{2} \mathrm{O}_{2}$ was added at a rate of $3 \mathrm{ml} / \mathrm{h}$ for $24 \mathrm{~h}$. 


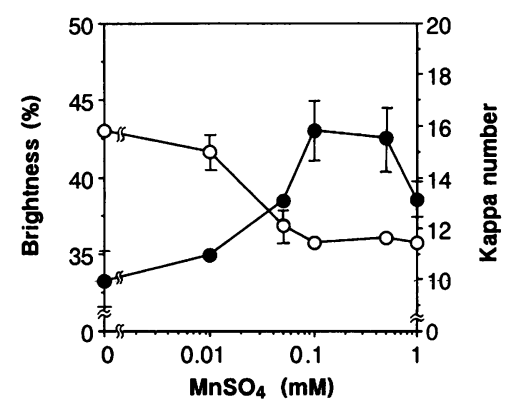

FIG. 7. Effect of $\mathrm{MnSO}_{4}$ concentration on brightness (๑) and kappa number $(O)$ of kraft pulp treated with MnP. Reactions were performed with $100 \mathrm{U}$ of $\mathrm{MnP}$, and $10 \mathrm{mM}$ aqueous $\mathrm{H}_{2} \mathrm{O}_{2}$ was added at a rate of $3 \mathrm{ml} / \mathrm{h}$ for $24 \mathrm{~h}$.

brightness caused by fungal treatment are accompanied by decreases in kappa number and reductions in the lignin content as determined by the acetyl bromide method (9). The fungus secreted mainly $\mathrm{MnP}$, a trace of phenol oxidase, and no LiP during the biobleaching process $(7,9)$. The liquid culture used to prepare the enzyme solution also contained the same ligninolytic enzyme system. There have been several reports on lignin-degrading fungi that secrete $\mathrm{MnP}$ and laccase (coppercontaining phenol oxidase) but not LiP, including Dichomitus squalens (19), Lentinus edodes (12), and Stereum hirsutum (15). It has recently been reported that only MnP activity was detected in the supernatant of $P$. sordida cultures (21).

$\mathrm{MnP}$ is a heme-containing enzyme which was first isolated from the extracellular medium of ligninolytic cultures of the white rot basidiomycete $P$. chrysosporium $(10,18)$. MnP requires $\mathrm{H}_{2} \mathrm{O}_{2}$ as a cosubstrate and catalyzes the oxidation of $\mathrm{Mn}^{2+}$ to $\mathrm{Mn}^{3+}$. $\mathrm{Mn}^{3+}$ complexed with an organic acid (malonate, etc.) readily oxidizes phenolic lignin model compounds $(23,25,26)$. Although it has been reported that MnP catalyzes
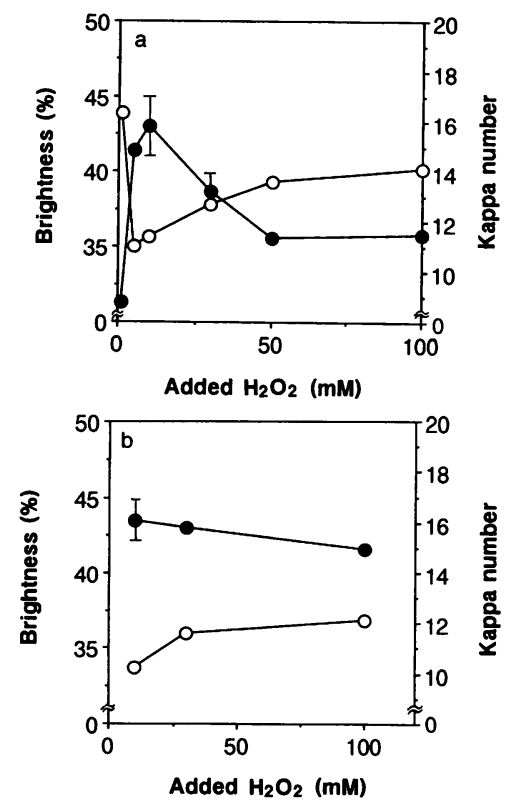

FIG. 8. Effect of the concentration of added $\mathrm{H}_{2} \mathrm{O}_{2}$ on brightness (O) and kappa number $(O)$ of kraft pulp treated with $100 \mathrm{U}$ (a) or

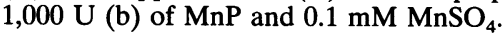

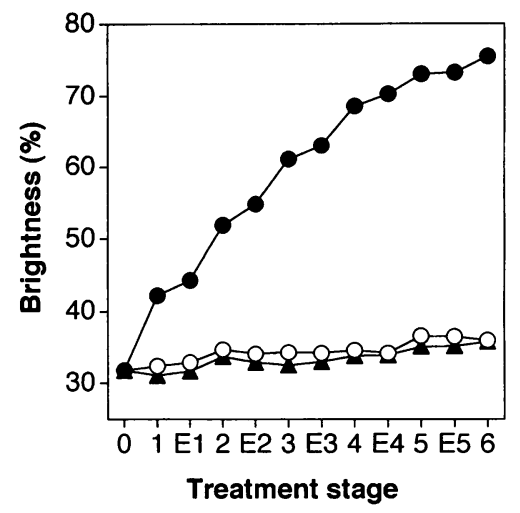

FIG. 9. Bleaching of kraft pulp with $\mathrm{MnP}$ combined with alkaline extraction. Symbols: $\bullet$, with $\mathrm{MnP} ; \mathrm{O}$, without $\mathrm{MnP} ; \boldsymbol{\Delta}$, without $\mathrm{H}_{2} \mathrm{O}_{2}$. Treatment stages 1 through $6, \mathrm{MnP}$ treatment; treatment stages E1 through E5, alkaline extraction.

the effective depolymerization of dehydropolymerizate (27) and high-molecular-weight chlorolignin $(11,13)$ in vitro in the presence of $\mathrm{MnSO}_{4}$ and $\mathrm{H}_{2} \mathrm{O}_{2}$, there have been no reports of studies in which extensive delignification and brightening of the kraft pulp were achieved with isolated MnP.

Therefore, we examined pulp treatment with MnP. First, we treated pulp with chemically prepared $\mathrm{Mn}^{3+}$ complexed with malonate in order to study the possibility that kraft pulp was delignified by isolated MnP. A nitrogen atmosphere maintained the stability of $\mathrm{Mn}^{3+}$-malonate complexes during long treatment by preventing the transformation of $\mathrm{Mn}^{3+}$ due to hydrolysis and disproportionation to $\mathrm{Mn}^{4+}\left(\mathrm{MnO}_{2}\right)$ and $\mathrm{Mn}^{2+}$ $(6,11)$. Multiple treatments with $20 \mathrm{mM} \mathrm{Mn}^{3+}$ combined with alkaline extraction resulted in brightening and delignification of pulp compared with the corresponding control without $\mathrm{Mn}^{3+}$ (Fig. 4). Lackner et al. oxidized polymeric chlorolignin $\left(M_{\mathrm{r}},>30,000\right)$ in dialysis tubing by using $\mathrm{Mn}^{3+}$ lactate as a biomimetic model for enzymatically generated $\mathrm{Mn}^{3+}(11)$. These authors showed that chlorolignin was degraded by $\mathrm{Mn}^{3+}$ and $\mathrm{MnP}$ in vitro.

Paice et al. reported that a culture filtrate containing MnP and $\mathrm{MnP}$ isolated from $T$. versicolor did not produce extensive delignification and brightening, although these preparations demethylated kraft pulp (17). On the other hand, we succeeded in delignifying residual lignin in kraft pulp with isolated MnP. MnP brightened the pulp by about 10 points and reduced the kappa number by about 6 points in the presence of $\mathrm{MnSO}_{4}$ and $\mathrm{H}_{2} \mathrm{O}_{2}$. When we repeated the MnP treatments six times in combination with alkaline extraction, the pulp brightness increased by 43 points. This brightening was comparable to that caused by whole fungal systems.

It is thought that $\mathrm{MnP}$ uses $\mathrm{Mn}^{2+}$ originally present in kraft pulp during fungal bleaching. However, pulp was not substantially delignified unless $\mathrm{Mn}^{2+}$ was added during in vitro bleaching with MnP (Fig. 7). During fungal bleaching, the action of mycelia (e.g., penetration of mycelia into pulp) may increase the contact between $\mathrm{MnP}$ and $\mathrm{Mn}^{2+}$ in pulp and help the MnP catalytic cycle. The amount of $\mathrm{H}_{2} \mathrm{O}_{2}$ added to a pulp suspension influenced the catalytic action of $\mathrm{MnP}$ significantly. MnP activity and LiP activity are eliminated by excess $\mathrm{H}_{2} \mathrm{O}_{2}$ (25). The delignification observed with $100 \mathrm{U}$ of $\mathrm{MnP}$ was considerably influenced by the $\mathrm{H}_{2} \mathrm{O}_{2}$ concentration (Fig. 8a). However, bleaching with $1,000 \mathrm{U}$ of $\mathrm{MnP}$ was less sensitive to the rate of addition of $\mathrm{H}_{2} \mathrm{O}_{2}$ (Fig. 8b).

When the pulp was treated with MnP without Tween 80 , the 
brightness increased by only about 4 points. It has been observed that addition of surfactants, such as Tween 80 , Tween 20, and 3-[(3-cholamidopropyl) dimethyl ammonio]-1-propanesulfonate, to culture media enhances ligninolytic enzyme production in agitated cultures of $P$. chrysosporium (8). It has been suggested that these surfactants protect ligninolytic enzymes against mechanical inactivation due to agitation (24). Therefore, Tween 80 was added to our pulp suspension to maintain the MnP activity. A surfactant may also disperse hydrophobic degraded lignin in water solutions easily and interfere with degraded lignin repolymerization.

\section{REFERENCES}

1. Addleman, K., and F. Archibald. 1993. Kraft pulp bleaching and delignification by dikaryons and monokaryons of Trametes versicolor. Appl. Environ. Microbiol. 59:266-273.

2. Arbeloa, M., J. Leclerc, G. Goma, and J. C. Pommier. 1992. An evaluation of the potential of lignin peroxidases to improve pulp. TAPPI (Tech. Assoc. Pulp Pap. Ind.) J. 75:215-221.

3. Bourbonnais, R., and M. G. Paice. 1992. Demethylation and delignification of kraft pulp by Trametes versicolor laccase in the presence of 2,2'-azinobis(3-ethylbenzthiazoline-6-sulphonate). Appl. Microbiol. Biotechnol. 36:823-827.

4. Fujita, K., R. Kondo, K. Sakai, Y. Kashino, T. Nishida, and Y. Takahara. 1991. Biobleaching of kraft pulp using the white-rot fungus IZU-154. TAPPI (Tech. Assoc. Pulp Pap. Ind.) J. 74(11): 123-127.

5. Fujita, K., R. Kondo, K. Sakai, Y. Kashino, T. Nishida, and Y. Takahara. 1993. Biobleaching of softwood kraft pulp with whiterot fungus IZU-154. TAPPI (Tech. Assoc. Pulp Pap. Ind.) J. 76(1):81-84.

6. Glenn, J. K., L. Akileswaran, and M. H. Gold. 1986. Mn(II) oxidation is the principal function of the extracellular Mn-peroxidase from Phanerochaete chrysosporium. Arch. Biochem. Biophys. 251:688-696.

7. Hirai, H., R. Kondo, and K. Sakai. 1994. Screening of lignindegrading fungi and ligninolytic enzyme activities during biological bleaching of kraft pulp. Mokuzai Gakkaishi 40:980-986.

8. Jäger, A., S. Croan, and T. K. Kirk. 1985. Production of ligninases and degradation of lignin in agitated submerged cultures of Phanerochaete chrysosporium. Appl. Environ. Microbiol. 50:1274 1278.

9. Kondo, R., K. Kurashiki, and K. Sakai. 1994. In vitro bleaching of hardwood kraft pulp by extracellular enzymes excreted from white rot fungi in a cultivation system using a membrane filter. Appl. Environ. Microbiol. 60:921-926.

10. Kuwahara, M., J. K. Glenn, M. A. Morgan, and M. H. Gold. 1984. Separation and characterization of two extracellular $\mathrm{H}_{2} \mathrm{O}_{2}$-dependent oxidases from ligninolytic cultures of Phanerochaete chrysosporium. FEBS Lett. 169:247-250.

11. Lackner, R., E. Srebotnik, and K. Messner. 1991. Oxidative degradation of high molecular weight chlorolignin by manganese peroxidase of Phanerochaete chrysosporium. Biochem. Biophys. Res. Commun. 178:1092-1098.

12. Leatham, G. F. 1986. The ligninolytic activities of Lentinus edodes and Phanerochaete chrysosporium. FEMS Microbiol. Lett. 24:5158.
13. Michael, F. C., S. B. Dass, E. A. Grulke, and C. A. Reddy. 1991. Role of manganese peroxidases and lignin peroxidases of Phanerochaete chrysosporium in the decolorization of kraft bleach plant effluent. Appl. Environ. Microbiol. 57:2368-2375.

14. Murata, S., R. Kondo, K. Sakai, Y. Kashino, T. Nishida, and Y. Takahara. 1992. Chlorine-free bleaching process of kraft pulp using treatment with the fungus IZU-154. TAPPI (Tech. Assoc. Pulp Pap. Ind.) J. 75(12):91-94.

15. Nerud, F., Z. Zouchova, and Z. Misurcovaz. 1991. Ligninolytic properties of different white-rot fungi. Biotechnol. Lett. 13:657660.

16. Paice, M. G., L. Jurasek, C. Ho, R. Bourbonnais, and F. S. Archibald. 1989. Direct biological bleaching of hardwood kraft pulp with fungus Coriolus versicolor. TAPPI (Tech. Assoc. Pulp Pap. Ind.) J. 72(5):217-221.

17. Paice, M. G., I. D. Reid, R. Bourbonnais, F. S. Archibald, and L. Jurasek. 1993. Manganese peroxidase, produced by Trametes versicolor during pulp bleaching, demethylates and delignifies kraft pulp. Appl. Environ. Microbiol. 59:260-265.

18. Paszczynski, A., V. B. Huynh, and R. Crawford. 1985. Enzymic activities of an extracellular, manganese-dependent peroxidase from Phanerochaete chrysosporium. FEMS Microbiol. Lett. 29:3741.

19. Périé, F. H., and M. H. Gold. 1991. Manganese regulation of manganese peroxidase expression and lignin degradation by the white rot fungus Dichomitus squalens. Appl. Environ. Microbiol. 57:2240-2245.

20. Reid, I. D., M. G. Paice, C. Ho, and L. Jurasek. 1990. Biological bleaching of softwood kraft pulp with the fungus Trametes versicolor. TAPPI (Tech. Assoc. Pulp Pap. Ind.) J. 73(8):149-153.

21. Rüttimann-Johnson, C., D. Cullen, and R. T. Lamar. 1994. Manganese peroxidases of the white rot fungus Phanerochaete sordida. Appl. Environ. Microbiol. 60:599-605.

22. Tien, M., and T. Kirk. 1988. Lignin peroxidase of Phanerochaete chrysosporium. Methods Enzymol. 161:238-249.

23. Tuor, U., H. Wariishi, H. E. Schoemaker, and M. H. Gold. 1992. Oxidation of phenolic arylglycerol $\beta$-aryl ether lignin model compounds by manganese peroxidase from Phanerochaete chrysosporium: oxidative cleavage of an $\alpha$-carbonyl model compound. Biochemistry 31:4986-4995.

24. Venkatadri, R., and R. Irvine. 1990. Effect of agitation on ligninase activity and ligninase production by Phanerochaete chrysosporium. Appl. Environ. Microbiol. 56:2684-2691.

25. Wariishi, H., L. Akileswaran, and M. H. Gold. 1988. Manganese peroxidase from the basidiomycete Phanerochaete chrysosporium: spectral characterization of the oxidized states and the catalytic cycle. Biochemistry 27:5365-5370.

26. Wariishi, H., K. Valli, and M. H. Gold. 1989. Oxidative cleavage of a phenolic diarylpropane lignin model dimer by manganese peroxidase from Phanerochaete chrysosporium. Biochemistry 28:60176023.

27. Wariishi, H., K. Valli, and M. H. Gold. 1991. In vitro depolymerization of lignin by manganese peroxidase of Phanerochaete chrysosporium. Biochem. Biophys. Res. Commun. 176:269-276.

28. Wariishi, H., K. Valli, V. Reganathan, and M. H. Gold. 1989. Tiol-mediated oxidation of nonphenolic lignin model compounds by manganese peroxidase of Phanerochaete chrysosporium. J. Biol. Chem. 264:14185-14191. 